\title{
PÓS-TRATAMENTO DE LIXIVIADO DE ATERRO SANITÁRIO POR COAGULAÇÃO - FLOCULAÇÃO - SEDIMENTAÇÃO/FLOTAÇẪO COM ADIÇÃO DE POLÍMEROS
}

\author{
Renan Borelli Galvão ${ }^{1}$
}

\author{
Nicolas Weis de Souza Pauli ${ }^{2}$
}

Emília Kiyomi Kuroda ${ }^{3}$

\begin{abstract}
RESUMO
O lixiviado de aterro sanitário pode conter quantidades consideráveis de matéria orgânica, nitrôgenio amoniacal, metais pesados, sais inorgânicos e organoclorados, que são tóxicos aos organismos vivos e ecossistemas e necessitam de tratamento adequado antes de sua disposição final em corpos hídricos receptores. O tratamento deste efluente pode requerer uma combinação de técnicas e processos biológicos e físico-químicos, a depender da qualidade desejável do efluente. Este trabalho teve como objetivo avaliar, de forma prospectiva, a eficiência da coagulação - floculação e separação por sedimentação ou flotação como pós-tratamento de lixiviado de aterro sanitário, em relação a remoção de matéria orgânica recalcitrante correlacionada à cor verdadeira. Os ensaios foram realizados em equipamentos de bancada com dosagem de Fe de $400 \mathrm{mg} \mathrm{L}^{-1}$ em $\mathrm{pH} 4,0 \mathrm{com}$ ou sem adição de $2 \mathrm{mg} \mathrm{L}^{-1}$ de polímeros não iônico, catiônico e aniônico. As condições de maior eficiência após sedimentação e flotação foram obtidas com a utilização de polímero catiônico como auxiliar de floculação atingindo valores máximos de remoção de cor verdadeira de 99,95\% e 100\%, respectivamente.
\end{abstract}

PALAVRAS-CHAVE: Pós-tratamento de lixiviado. Tratamento físico-químico. Coagulação - floculação sedimentação/flotação.

\footnotetext{
${ }_{1}^{1}$ Discente do curso de Engenharia Civil, Universidade Estadual de Londrina. renan_bg7th@msn.com

${ }^{2}$ Discente do curso de Engenharia Civil, Universidade Estadual de Londrina. nicolas_wsp@hotmail.com

${ }^{3}$ Professora Doutora, Dpto. de Construção Civil, Universidade Estadual de Londrina. ekkuroda@uel.br
} 


\title{
POST-TREATMENT OF SANITARY LANDFILL LEACHATE BY COAGULATION-FLOCCULATION- SEDIMENTATION/FLOTATION WITH POLYMER ADITION
}

\begin{abstract}
Sanitary landfill leachate may contain considerable amounts of organic matter, ammonia, heavy metals, inorganic salts and organochlorines, which are toxic to living organisms and ecosystems and require appropriate treatment before final disposal into water bodies. The treatment of this effluent sometimes require a combination of biological and physico-chemical processes, depending on the desired effluent quality. This study aimed to evaluate, prospectively, the efficiency of coagulation - flocculation and separation by sedimentation or flotation as post-treatment of landfill leachate in relation to the removal of recalcitrant organic matter correlated to true color. Experiments were performed in bench scale, with a Fe dosage of $400 \mathrm{mg} \mathrm{L}^{-1}$ at $\mathrm{pH} 4.0$, with or without addition of $2 \mathrm{mg} \mathrm{L}^{-1}$ of nonionic, anionic and cationic polymers. The maximum efficiency conditions after sedimentation and flotation were obtained using cationic polymer as a flocculation aid reaching maximum removal of true color of $99.95 \%$ and $100 \%$, respectively.
\end{abstract}

KEY-WORDS: Post-treatment of sanitary landfill leachate. Physico-chemical Treatment. Coagulation flocculation - sedimentation/flotation.

\section{POST-TRATAMIENTO DE LIXIVIADOS DE RELLENO SANITARIO POR COAGULACIÓN-FLOCULACIÓN- SEDIMENTACION/FLOTACIÓN CON ADICIÓN DE POLÍMERO}

\begin{abstract}
RESUMEN
EI lixiviado de rellenos sanitarios puede contener cantidades considerables de materia orgánica, amoníaco, metales pesados, sales inorgánicos y compuestos organoclorados, que son tóxicos para los organismos vivos y los ecosistemas y que requieren un tratamiento adecuado antes de su disposición final en cuerpos de agua. El tratamiento de este efluente a veces puede requerir una combinación de procesos biológicos y físico-químicos, dependiendo de la calidad del efluente deseada. Este estudio tuvo como objetivo evaluar, de forma prospectiva, la eficiencia de la coagulación - floculación y separación por sedimentación o flotación como post-tratamiento de lixiviados de relleno sanitario en relación con la eliminación de la materia orgánica recalcitrante correlacionado con el verdadero color. Los ensayos se realizaron en un equipo de prueba de dosificación Fe $400 \mathrm{mg} \mathrm{L}^{-1}$ a pH 4,0 con o sin adición de $2 \mathrm{mg} \mathrm{L}^{-1}$ de polímeros no iónicos, aniónicos y catiónicos. Las condiciones para una mayor eficiencia después de la sedimentación y flotación se obtuvieron con el uso de polímero catiónico y la máxima extracción de color verdadero de 99,95\% y 100\%, respectivamente.
\end{abstract}

PALABRAS-CLAVE: Post-tratamiento de lixiviados. Tratamiento físico-químico. Coagulación - floculación sedimentación / flotación. 


\section{INTRODUÇÃO}

As atividades comerciais, industriais e agrícolas realizadas pelo homem geram em seu processo uma grande quantidade de resíduos sólidos. No decorrer das últimas décadas, o desenvolvimento tecnológico aliado à mudança do estilo de vida da população moderna, promoveram grande aumento da produção destes resíduos, fazendo com que a destinação final dos mesmos se tornasse uma grande e importante preocupação.

A crescente urbanização e industrialização de cidades, juntamente com o ritmo de vida e consumismo acelerados, são responsáveis pelo aumento da geração de resíduos. Estes são provenientes de diversas fontes e processos de produção, gerando um montante com características heterogêneas, e precisam ser destinados a processos de reutilização/reciclagem ou a locais preparados adequadamente para este fim.

A disposição de resíduos urbanos em aterros sanitários é uma das formas de disposição mais viável técnica e economicamente para realidade brasileira. Os aterros devem possuir sistemas de drenagem de águas superficiais e, por se tratarem de obras de confinamento de resíduos, devem ser impermeabilizados de maneira a impedir que a água percolada se infiltre e atinja os lençóis freáticos. O lixiviado de aterro sanitário, comumente chamado percolado ou chorume, pode conter quantidades consideráveis de matéria orgânica, nitrôgenio amoniacal, metais pesados, sais inorgânicos e organoclorados, que são tóxicos aos organismos vivos e ecossistemas e necessitam de tratamento adequado antes de sua disposição final em corpos hídricos receptores (WEl et al., 2010).

O tratamento de lixiviado pode ser baseado em processos biológicos e físicoquímicos. O tratamento biológico pode ocorrer por processos aeróbios, anaeróbios e facultativos, entretanto, apresentam baixa eficiência na remoção de compostos recalcitrantes e coloridos. O tratamento físico-químico por sua vez, apresenta maior eficiência na remoção de compostos recalcitrantes quando comparados ao tratamento biológico, podendo-se destacar, entre outros, a coagulação - floculação - 
sedimentação/flotação, adsorção, filtração por membranas, oxidação avançada e precipitação química. Sendo assim, o tratamento do lixiviado pode por vezes, requerer uma combinação de técnicas e processos biológicos e físico-químicos, a depender da qualidade desejável do efluente.

O pós-tratamento de lixiviado por coagulação - floculação - sedimentação e sua eficiência quanto a remoção de matéria orgânica recalcitrante vem sendo estudado por diversos autores (KAWAHIGASHI, 2012; MALER, 2013; POZZETTI, 2014). O pós-tratamento físico-químico citado ocorre em três etapas distintas.

A coagulação é um processo que promove a desestabilização de partículas através da adição de um agente coagulante com carga positiva contrária as partículas carregadas, geralmente sais de ferro ou alumínio ou polímeros, que anula as forças de repulsão entre as partículas pela eliminação da barreira de energia. A desestabilização é um processo interativo coagulante-colóide controlado por parâmetros físicos, tais como gradiente de velocidade, tempo e temperatura, e químicos, como pH, concentração de coagulante e natureza das impurezas (DI BERNARDO e DANTAS, 2005).

A floculação, etapa posterior à coagulação, baseia-se na ocorrência de choques entre as partículas, sob um gradiente de velocidade fornecido ao sistema, que se aderem umas as outras devido às forças de atração atuantes, formando flocos cada vez maiores, mais densos e de maior volume. Em um segundo estágio, na formação de flocos grandes podem ser utilizados polieletrólitos com cargas elétricas fracas ou moderadas. A floculação ocorre por adsorção do polieletrólito na superfície da partícula, formando pontes através de outras partículas, juntando-as como um grande floco (DI BERNARDO e DANTAS, 2005).

Por fim, dá-se a etapa de separação das fases por meio dos processos de sedimentação ou flotação. A sedimentação é o processo de deposição das partículas floculadas mais densas que a água pela ação da força da gravidade, promovendo assim a clarificação do efluente. A flotação consiste na separação de fases sólidolíquido através do movimento ascendente de flocos, onde as forças de empuxo 
predominam sobre as gravitacionais, por diferença de densidade ou por introdução de microbolhas de ar dissolvido (DI BERNARDO e DANTAS, 2005).

A flotação tem sido usada extensivamente no tratamento de efluentes industriais. No entanto, poucos estudos tem sido voltados à aplicação desta técnica para o tratamento de lixiviado de aterro sanitário. Assim, faz-se necessário o estudo e investigação dessa alternativa técnica, visando a avaliação de seu desempenho em relação às legislações vigentes e obtenção de parâmetros operacionais e de projeto.

\section{DESENVOLVIMENTO}

\subsection{Material e métodos}

O lixiviado bruto utilizado nos ensaios foi proveniente do aterro controlado da cidade de Londrina - PR. Após coleta do lixiviado, todo o volume foi acondicionado em tanque de 15,0 $\mathrm{m}^{3}$, localizado nas dependências do Laboratório de Saneamento da UEL.

O tratamento biológico do lixiviado foi realizado em duas etapas. A primeira consistiu no emprego da técnica de stripping de amônia em sistemas de bateladas sequenciais para remoção parcial de $\mathrm{N}$-amoniacal. A segunda etapa deu-se através da utilização do tratamento biológico por lodos ativados, composto por fase aeróbia, seguido de fase anóxica com adição de etanol como fonte de carbono, dosado em função das concentrações de nitrito e nitrato residuais para desnitrificação por via curta e consequente remoção da série nitrogenada.

Os ensaios de pós-tratamento físico-químico por coagulação - floculação e separação por sedimentação e/ou flotação foram realizados em escala de bancada utilizando os seguintes equipamentos:

- Jarteste (Nova Ética - 218/6LDBE), composto de tacômetro digital para visualização da rotação (até $600 \mathrm{rpm} \pm 2 \%$ ), conferindo um gradiente de velocidade de até $1.200 \mathrm{~s}^{-1}$ e dispositivo para aplicação de produtos químicos e coleta de água simultâneas nos 6 jarros. 
- Floteste (ETHIK TECHNOLOGY, modelo 218-3 FLOW), composto de 3 jarros de acrílico transparente de $2 \mathrm{~L}$, com placa de fundo perfurada a fim de possibilitar a introdução e distribuição uniforme de água saturada com ar, uma câmara de pressurização com volume útil de $2 \mathrm{~L}$ e válvula reguladora de pressão com filtro.

As condições de coagulação química foram as mesmas estabelecidas como de máxima eficiência por Pozetti (2014) e De Castro (2012) que utilizaram o mesmo lixiviado: dosagem de Fe de $400 \mathrm{mg} \mathrm{L}^{-1} \mathrm{em} \mathrm{pH} \mathrm{4,0,} \mathrm{com} \mathrm{ou} \mathrm{sem} \mathrm{adição} \mathrm{de} 2 \mathrm{mg} \mathrm{L}^{-1}$ de polímeros não iônico, catiônico e aniônico.

Os valores e parâmetros de controle operacional utilizados nos ensaios são apresentados na Tabela 1.

Tabela 1: Valores e parâmetros de controle operacional

\begin{tabular}{cc}
\hline Tempo médio de mistura rápida (Tmr) & $1 \mathrm{~min}$ \\
\hline Gradiente de velocidade médio de mistura rápida (Gmr) & $600 \mathrm{~s}^{-1}$ \\
\hline Tempo médio de floculação (Tfloc) & $20 \mathrm{~min}$ \\
\hline Gradiente de velocidade médio de floculação (Gfloc) & $20 \mathrm{~s}^{-1}$ \\
\hline Taxa de Recirculação - R & $50 \%$ e $100 \%$ \\
\hline Pressão da Câmara de Saturação - P & $500 \mathrm{kPa}$ \\
\hline Tempo de Saturação - Tsat & $8 \mathrm{~min}$ \\
\hline Velocidades de sedimentação (Vsed) & 0,05 e $0,1 \mathrm{~cm} \mathrm{~min}^{-1}$ \\
\hline Velocidades ascencionais (Vasc) & $0,1 \mathrm{e} 1 \mathrm{~cm} \mathrm{~min}^{-1}$ \\
\hline
\end{tabular}

Fonte: o próprio autor.

Os produtos químicos utilizados foram:

- Solução comercial de ácido clorídrico com $37 \%$ em massa e massa específica $=1,187 \mathrm{~kg} \mathrm{~L}^{-1}$ como acidificante;

- Solução comercial de cloreto férrico líquido com 38,94\% de $\mathrm{FeCl}_{3} \cdot 6 \mathrm{H}_{2} \mathrm{O}$, massa específica $=1,412 \mathrm{~kg} \mathrm{~L}^{-1}$ e cor amarela como coagulante; 
- Polieletrólitos catiônico (C8392 - carga 10\%), não iônico (N300 - carga 0\%) e aniônico (A130 - carga 30\%), a base de poliacrilamida, da marca Kemira.

Após coleta, as amostras foram filtradas em membrana de poliéster de celulose de $0,45 \mu \mathrm{m}$ de abertura e analisadas por espectrofotometria à $405 \mathrm{~nm}$ (Bel S05) para determinação da cor verdadeira.

\subsection{Resultados e discussão}

O efluente oriundo da etapa de tratamento biológico apresentou $\mathrm{pH}$ de 8,5 , alcalinidade de $1608 \mathrm{mg} \mathrm{CaCO}_{3} \mathrm{~L}^{-1}$ e cor verdadeira de $3393 \mathrm{uH}$.

A Figura 1 apresenta os resultados obtidos após o pós-tratamento físicoquímico por coagulação - floculação e separação por sedimentação ou flotação, quanto a remoção de matéria orgânica recalcitrante correlacionada à cor verdadeira.

Figura 1: Valores de cor verdadeira residual das amostras dos ensaios de jarteste e floteste

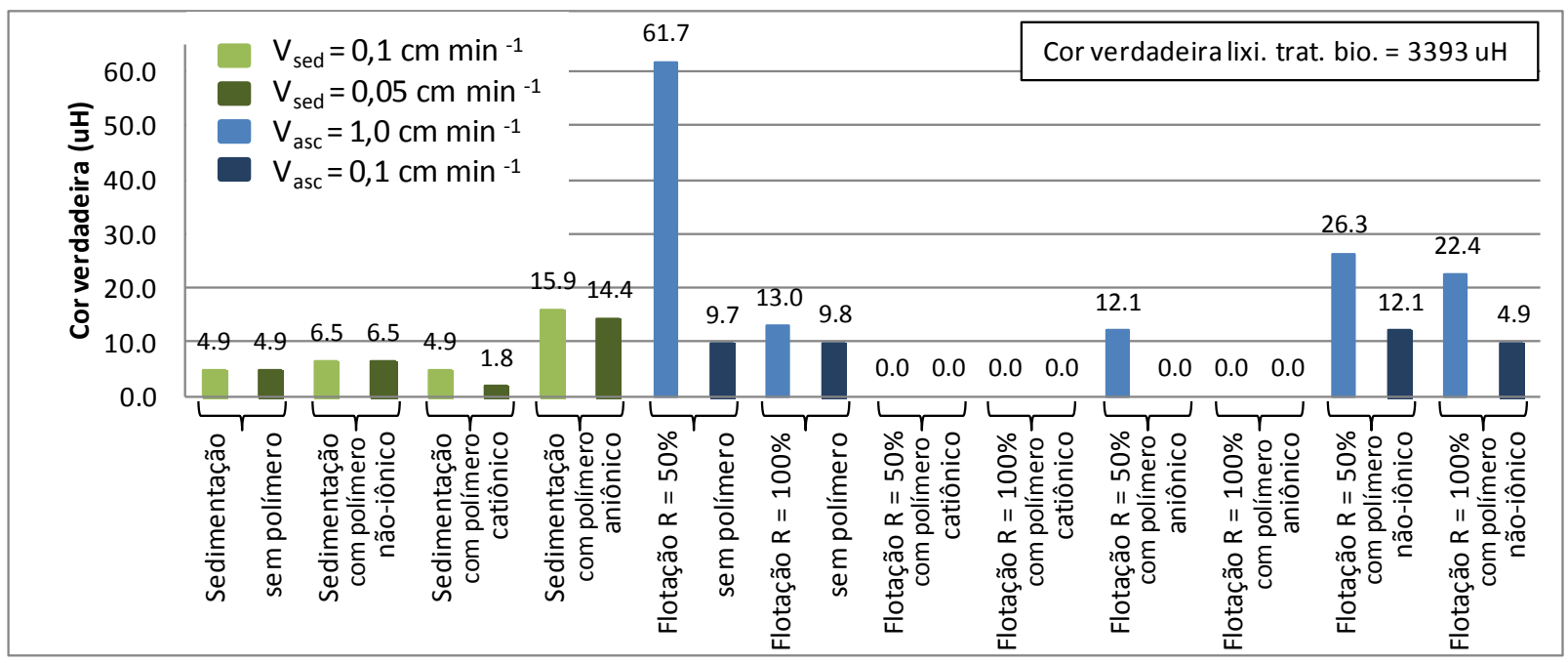

Fonte: o próprio autor.

No pós-tratamento por coagulação - floculação sem utilização de polímeros pode-se observar que, para as condições estudadas, a sedimentação (com porcentagem de remoção de $99,86 \%$ ) foi mais eficiente quando comparada a flotação (com porcentagens de remoção de 98,18 a 99,71\%) para remoção de cor verdadeira. 
Comparando os resultados obtidos após sedimentação com adição de polímeros, pôde-se observar que o polímero que mais contribuiu para remoção de cor verdadeira foi o polímero catiônico com porcentagens de remoção de 99,86 a 99,95\% de cor verdadeira.

Quanto ao pós-tratamento por flotação, a adição de polímeros catiônico e aniônico mostraram maior eficiência na remoção de cor verdadeira em relação ao não iônico, apresentando para o polímero aniônico e taxas de recirculação de 50 e 100\%, porcentagens de remoção de 99,64 e 100\%, respectivamente, e para o polímero catiônico, de 100\% para ambas as taxas de recirculação.

As condições de maior eficiência após sedimentação e flotação foram obtidas quando utilizou-se o polímero catiônico como auxiliar de floculação com valores máximos de remoção de $99,95 \%$ e 100\%, respectivamente.

Todas as amostras obtidas nas condições e tratamentos considerados neste trabalho atenderam ao valor limite de cor verdadeira de $75 \mathrm{uH}$ estabelecido pelo padrão de enquadramento da Resolução CONAMA 357/2005, para águas doces classes 2 e 3 , podendo-se constatar que o tratamento físico-químico foi eficiente para remoção de matéria orgânica recalcitrante correlacionada à cor verdadeira.

É importante destacar, porém, que as altas taxas de recirculação utilizadas nos ensaios podem inviabilizar a aplicação da coagulação - floculação - flotação em escala real. Neste aspecto, a separação por flotação mostrou-se ineficiente, pois mesmo a aplicação de elevadas taxas de recirculação (chegando a 100\%) não foi suficiente para promover a total flotação dos flocos formados, sendo ainda a operação de sedimentação, responsável por parte da separação das fases. Este fenômeno pode ser observado na Figura 2 em dois estágios da sedimentação/flotação, para a condição de tratamento com taxa de recirculação de $100 \%$ e adição de polímero catiônico. 
Figura 2: Fotos dos jarros no ensaio de flotação para $R=100 \%$ e adição de polímero catiônico, correspondentes às Vasc $=1,0(A)$ e $0,1(B) \mathrm{cm} \mathrm{min}^{-1}$
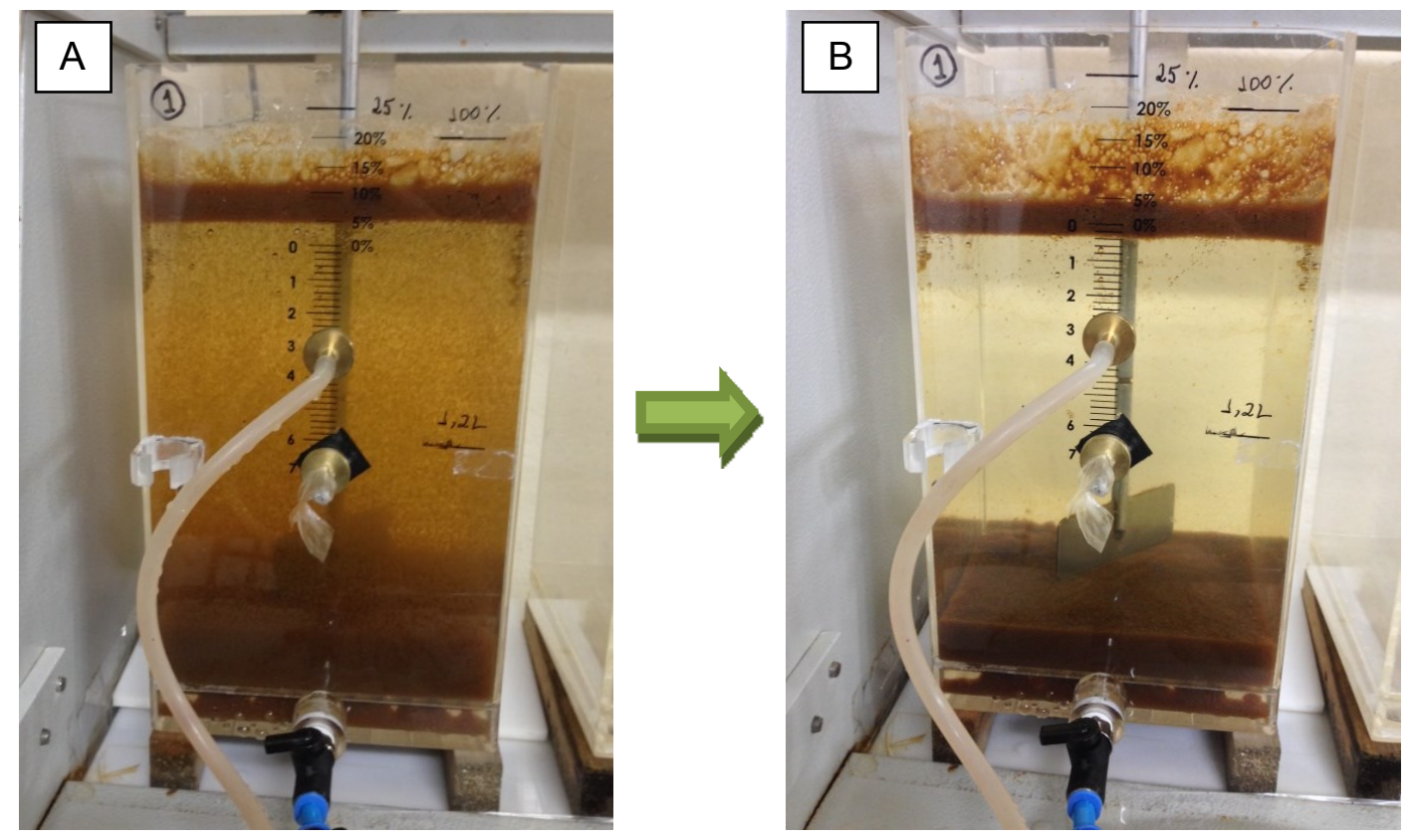

Fonte: o próprio autor.

\section{CONCLUSÃO}

As condições de maior eficiência após sedimentação e flotação foram obtidas quando utilizou-se o polímero catiônico como auxiliar de floculação com valores máximos de remoção de 99,95\% e 100\%, respectivamente.

Todas as amostras obtidas nas condições e tratamentos considerados neste trabalho atenderam ao valor limite de cor verdadeira de $75 \mathrm{uH}$ estabelecido pelo padrão de enquadramento da Resolução CONAMA 357/2005, para águas doces classes 2 e 3, podendo-se constatar que o tratamento físico-químico proposto foi 
eficiente para remoção de matéria orgânica recalcitrante correlacionada à cor verdadeira.

Para obtenção de eficiências similares às obtidas por sedimentação, a aplicação da flotação mostrou-se limitada, devido às elevadas taxas de recirculação requeridas, sendo ainda a operação de sedimentação, responsável por parte da separação das fases.

\section{REFERÊNCIAS}

BRASIL, Ministério do Meio Ambiente. Conselho Nacional de Meio Ambiente. Resolução $\mathbf{N}^{\circ} 357,17$ de março de 2005.

CASTRO, A. P. Influência da adição de polieletrólito no processo de floculação como póstratamento de lixiviado de aterro sanitário visando á remoção de carga orgânica recalcitrante. 2012. Dissertação (Mestrado em Engenharia de Edificações e Saneamento) - Universidade Estadual de Londrina. Londrina, 2012.

DI BERNARDO, L.; DANTAS, A. B. Métodos e técnicas de tratamento de água. $2^{a}$ ed., v. 1 , São Carlos: RiMa, 2005.

KAWAHIGASHI, F. Aplicabilidade do pós-tratamento de lixiviados de aterro sanitário por adsorção em carvão ativado granular e avaliação ecotoxicológica. 2012. Dissertação apresentada ao Programa de Pós-Graduação em Engenharia de Edificações e Saneamento, Universidade Estadual de Londrina, Londrina, 2012.

MALER, C. L. Aplicação do processo Fenton a diferentes etapas do tratamento de lixiviados de aterro sanitário. 2013. Dissertação apresentada ao Programa de Pós-Graduação em Engenharia de Edificações e Saneamento, Universidade Estadual de Londrina, Londrina, 2013.

POZZETTI, Jandiara D. C. Pós-tratamento de lixiviado de aterro sanitário por coagulação química-floculação-sedimentação, adsorção em carvão ativado pulverizado e avaliação ecotoxicológica. 2014. 100 páginas. Dissertação (Mestrado em Engenharia de Edificações e Saneamento) - Universidade Estadual de Londrina, Londrina, 2014.

WEI, L.; TAO, H.; QIXING, Z.; SHUGUANG, Z.; FENGXIANG, L. Treatment of stabilized landfill leachate by the combined process of coagulation/flocculation and powder activated carbon adsorption. Desalination, v. 264, n. 1, p. 56-62, Ago. 2010. 